\title{
Prediction of groundwater level in basement complex terrain using artificial neural network: a case of Ijebu-Jesa, southwestern Nigeria
}

\author{
K. A. N. Adiat ${ }^{1}$ - O. F. Ajayi ${ }^{1}$ A. A. Akinlalu' ${ }^{1}$ I. B. Tijani ${ }^{2}$ \\ Received: 17 March 2018 / Accepted: 30 October 2019 / Published online: 15 November 2019 \\ (c) The Author(s) 2019
}

\begin{abstract}
Empirical relationship between geoelectric parameters and groundwater level in boreholes/wells has not been established. Also, prediction of groundwater level from geoelectric parameters had hitherto not been reported. In order to overcome these challenges, the capability of artificial neural network (ANN) to model nonlinear system was explored in this study to predict groundwater level from geoelectric parameters. To achieve the above objectives, the ground water level (GWL) of all the accessible wells in the study area was obtained and this was used as the output parameter for the ANN model. A total of fifty-one (51) parametric vertical electrical soundings (VES) stations were occupied at each of the well location by adopting Schlumberger array configuration with electrode spacing $(\mathrm{AB} / 2)$ ranging from 1 to $100 \mathrm{~m}$. The VES data were quantitatively interpreted to generate geoelectric parameters believed to be controlling the groundwater flow and storage in the area. These parameters served as input for ANN model. The capability of ANN as a nonlinear modeling system was thereafter applied to produce a model that can predict the GWL from the input parameters. The efficiency of the model was evaluated by estimating the mean square error (MSE) and the regression coefficient $(R)$ for the model. The results established that seasonal variation has little effect on the water fluctuation in the wells. Two aquifer types, weathered and fractured basement aquifer types, were delineated in the area. The results of the ANN model validation showed low MSE of 0.0014286 and the high regression coefficient $(R)$ of 0.98731 . This indicates that ANN can be used to predict GWL in a basement complex terrain with reasonably good accuracy. It is concluded that the ANN can effectively predict GWL from geoelectric parameters.
\end{abstract}

Keywords Electrical resistivity $\cdot$ Schlumberger array $\cdot$ Artificial neural network $\cdot$ Prediction model

\section{Introduction}

Water is the elixir of life and is crucial for sustainable development. Earlier, it was considered to be a limitless or at least fully renewable natural resource. However, in the last 20 years or so, there has been a tremendous pressure on this

K. A. N. Adiat

kanadiat@futa.edu.ng

O. F. Ajayi

ofajayi@futa.edu.ng

A. A. Akinlalu

aaakinlalu@futa.edu.ng

I. B. Tijani

tijani.ismail@hct.ac.ae

1 Applied Geophysics Department, Federal University of Technology, Akure, Nigeria

2 Electronics Engineering, ADMC, Higher Colleges of Technology, Abu Dhabi, UAE precious natural resource mainly due to rapid industrialization and human population. This is because an increase in the human population will simply result in increasing the demand for irrigation purpose to meet food production requirements. Though, the advancement in agricultural technology has been impressive in many regions, poor irrigation management has resulted in considerable depletion of the groundwater table, damaged soils and deterioration in the water quality thus making the availability of water in the future highly uncertain. Keeping in mind the scarcity of available water resources in the near future and its impending threats, it has become imperative on the part of water scientists as well as planners to quantify the available water resources for its judicial use. Thus, a ready reckoner to monitor the fluctuations in groundwater levels well in advance is the need of the hour to devise sustainable water management protocols (Sreekanth et al. 2009).

Due to the reliability and sustainability of the resource, groundwater has been generally accepted to be the best

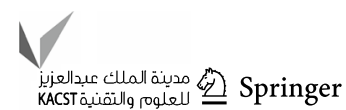


quality source of water for both drinking and irrigation purposes around the world (Hoque et al. 2009; Adiat et al. 2012). This, in addition to social development and agricultural production, has led to an increase in the awareness on the need to utilize and explore groundwater resources as alternative sources of water supply (Abdul et al. 2001).

Groundwater is reserved in the subsurface in a geologic system called aquifer. Groundwater level is an indicator of groundwater availability, groundwater flow and the physical characteristics of an aquifer or groundwater system (Nair and Sindhu 2016). A decrease in groundwater levels can trigger a number of eco-environmental problems capable of seriously affecting both local agricultural production and economic development (Li et al. 2019). Groundwater level is an important indicator of groundwater balance. Influence of climatic factors and human activities can make groundwater level exhibits cyclical and random characteristics. Therefore, the accurate prediction of groundwater level is of great significance for the rational utilization of groundwater resources and the sustainable development of the social economy (Li et al. 2019).

Electrical resistivity geophysical prospecting technique has been extensively utilized by many researchers in various domains of groundwater studies (Adiat et al. 2013). For instance, vertical electrical sounding (VES) technique can significantly contribute to the accurate location of aquifer not only through the development of its geometry (Zakari et al. 2015) but also by establishing relationship between the hydrogeological and geoelectrical parameters (Adiat et al. 2013).

An understanding of groundwater dynamics with the application of computer and mathematical tools can be used to predict groundwater flow and level fluctuation (Mao et al. 2002). In this direction, several studies were carried out for forecasting the groundwater levels using conceptual/ physical models that are not only laborious, but also have
Fig. 1 Regional geological map of Okemesi Fold Belt showing study area (adapted from Odeyemi 1993)

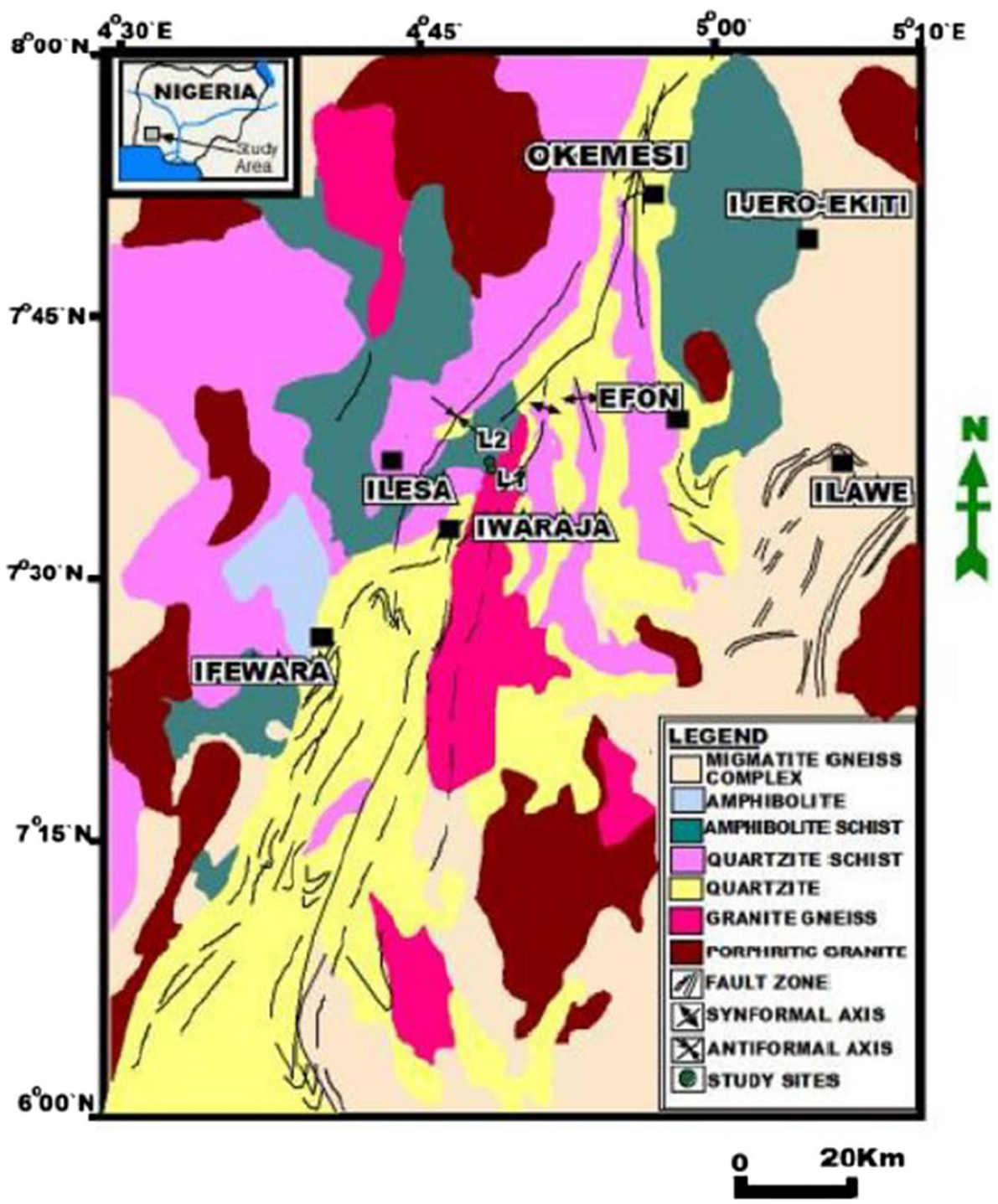


practical limitations (Daliakopoulos et al. 2005; Lallahem et al. 2005a, b) as many inter-related variables are involved. In the recent past, soft computing tools like artificial neural networks (ANNs) have been used increasingly in various fields of science and technology for prediction purposes (Brion et al. 2002). In particular, ANNs have been found useful in the area of groundwater modeling.

The ANN is a general-purpose model with a limited set of variables and is used as a universal functional approximator (Hornik 1991). It can forecast many nonlinear time series events (Hill et al. 1996; Tang and Fishwick 1993; Zhang 2003) over conventional simulation methods (French et al. 1992). Basically, ANNs are intelligent systems that are related in some way to a simplified biological model of the human brain. They are composed of many simple elements called neurons operating in parallel and connected to each other in the forward path by some multipliers called connection weights. Usually, ANNs are trained by adjusting the values of these connection weights between the network elements. ANNs have applications in various fields like forecasting, system identification, pattern recognition, classification, speech recognition, image processing, etc. Many studies on various aspects of groundwater studies have adopted ANN as a research tool. Such aspects of groundwater studies include, but not limited to, groundwater remediation (Gumrah et al. 2000; Zhao et al. 2007; Yan and Minsker 2006), subsurface characterization (Parkin et al. 2007), groundwater pollution (Gemitzi et al. 2009; Coppola et al. 2007) and parameter estimation (Aziz and Wong 1992; Ajmera and Rastogi 2008).

Simulation of karstic and leaky aquifers (Coppola et al. 2003), fluctuation of alluvial aquifer groundwater level (Esmaili 2003), evaluation of dynamic water level in karstic aquifer (Lallahem et al. 2005a, b), simulation of the effects of hydrological, weather and humidity conditions on groundwater level (Shaouuan et al. 2007), etc., has been carried out

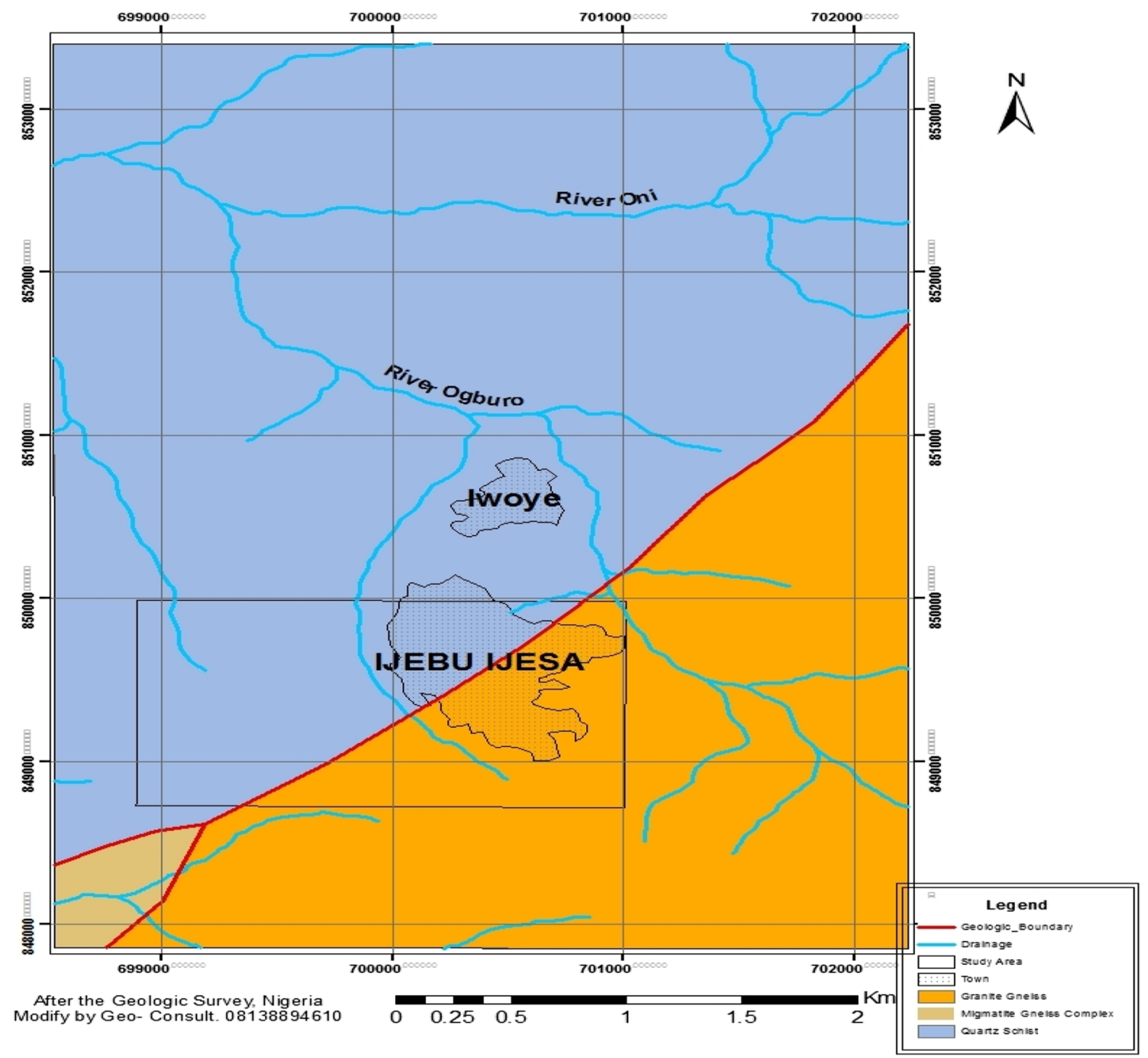

Fig. 2 Local geological map of the study area (modified after the Geologic Survey, Nigeria) 
by researchers around the world. It is, however, observed, within the context of literature review done for this study, that empirical relationship between geoelectric parameters and groundwater level has not been established in the literature. Furthermore, prediction of groundwater level from geoelectric parameters still remains a challenge that has hitherto not been carried out. More importantly, the capability of ANN has not been employed in this aspect of groundwater study in the study area. In order to overcome this challenge, an attempt would be made in this study to adopt ANN as a tool to predict groundwater level from geoelectric parameters. In addition to the attainment of the above aim, the study was also carried out to achieve the following objectives:

1. generate geoelectric parameters of hydrogeological importance;

2. produce piezometric head parameters;

3. establish nonparametric relationship between the input data, i.e., geoelectric parameters and groundwater level (i.e., the output) in the study area;

4. develop ANN and validate model for predicting groundwater column in basement complex terrain.

\section{Description of the study area}

The study area is Ijebu-Jesa, the capital of the Oriade Local Government Area of Osun state, southwestern Nigeria. It falls between latitude $7^{\circ} 40^{\prime} \mathrm{N}$ and $7^{\circ} 43^{\prime} \mathrm{N}$ and longitude $4^{\circ} 48^{\prime} \mathrm{E}$ and $4^{\circ} 50^{\prime} \mathrm{E}$. The topography of the area is gently undulating. The climate is well defined with wet and dry seasons with annual rainfall varying between 150 and $200 \mathrm{~cm}$. The annual relative humidity is over $80 \%$ with temperature ranging from 24 to $27^{\circ} \mathrm{C}$. The vegetation of the area is of rain forest.

The study area falls within the basement complex of the southwestern Nigeria. It forms part of the African crystalline shield which consists predominantly of migmatite and undifferentiated gneisses and quartzite (Rahaman 1976). The important structural features in the basement rocks include joints, faults, fractures, lineations and geological boundaries. These structural features are relevant in the control of groundwater accumulation and movement.

The major rock associations of this area form part of the Proterozoic Ilesha schist belt in southwestern part of Nigeria. This is predominantly developed in the western half of the country. In terms of structural features, lithology and

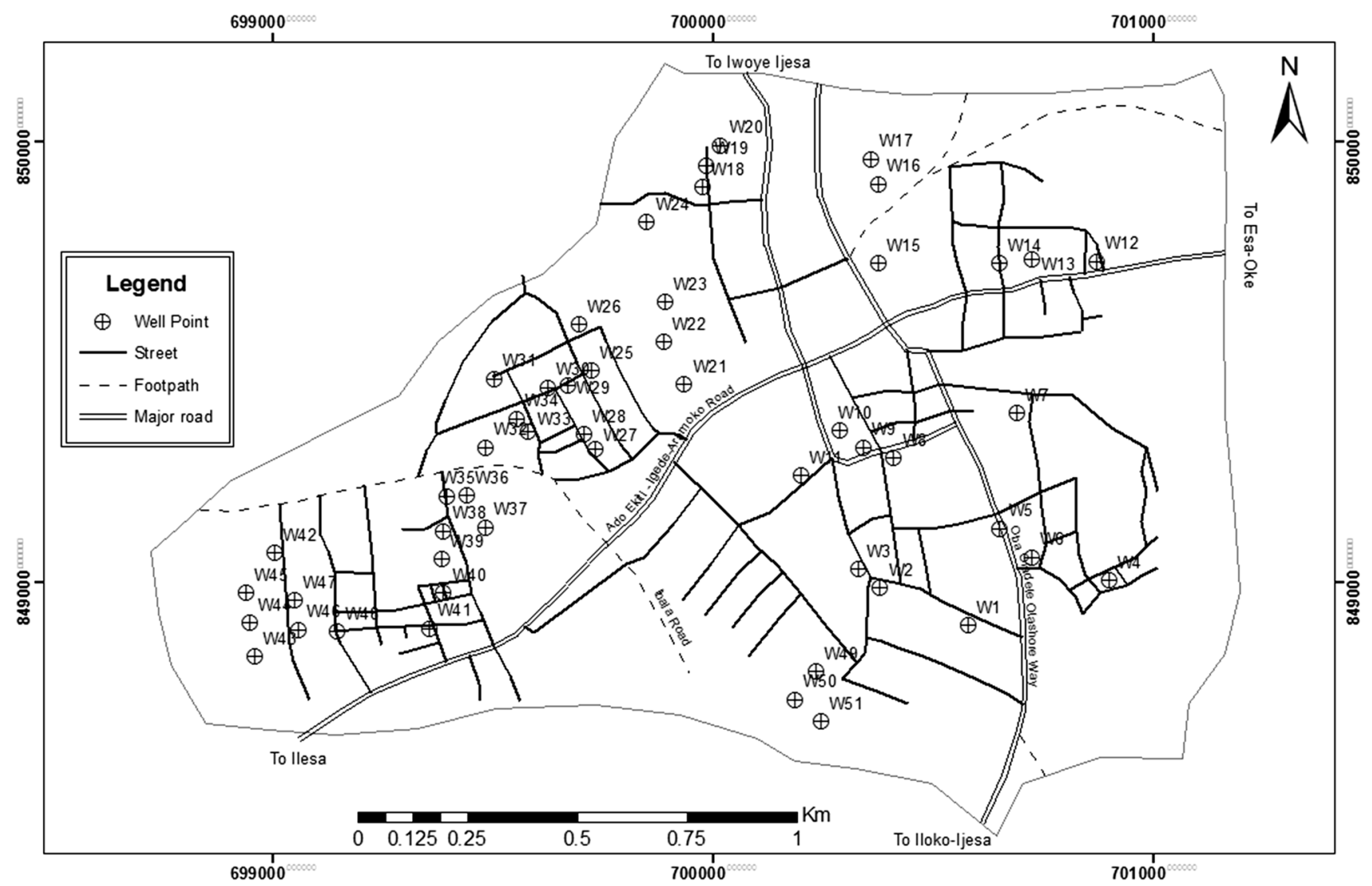

Fig. 3 Base map of the study area showing well/VES locations 
mineralization, the schist belts of Nigeria show considerable similarities to the Achaean green stone belts (Olusegun et al. 1995). However, the latter usually contain much larger proportions of mafic and ultramafic bodies and assemblages of lower metamorphic grade (Olusegun et al. 1995; Ajayi and Ogedengbe 2003).

Rocks in the Ilesha schist belt are structurally divided into two main segments by two major fracture zones often called the Iwaraja faults in the eastern part and the Ifewara faults in the western part (Elueze 1986; Folami 1992; Kayode 2006). The regional geological map showing the study area is shown in Fig. 1. The northern part of the fault comprises mostly of amphibolites, amphibole schist, meta-ultramafic and meta-pelites. Extensive psammitic units with minor meta-pelite constitute the eastern segment (Rahaman 1976). These are found as quartzite and quartz schist. All these assemblages are associated with migmatitic gneisses and are cut by a variety of granitic bodies (Rahaman 1976; Elueze 1986; Olusegun et al. 1995; Ajayi and Ogedengbe 2003).

The rocks of the Ilesha district may be broadly grouped into gneiss-migmatite complex, mafic-ultramafic suite (or amphibolites complex), meta-sedimentary assemblages and intrusive suite of granitic rocks. A variety of minor rock types are also related to these units. The gneiss-migmatite complex comprises migmatitic and granitic, calcareous and granulitic rocks. The mafic-ultramafic suite is composed mainly of amphibolites and amphibole schist and minor meta-ultramafites, made up of anthophyllite-tremolite-chlorite and talc schist (Rahaman 1976).

The meta-sedimentary assemblages, chiefly meta-pelites and psammitic units, are found as quartzite and quartz schist. The intrusive suite consists essentially of Pan African (c. $600 \mathrm{Ma}$.) granitic units. The minor rocks include garnet-quartz-chlorite bodies, biotite-garnet rock, syenitic bodies and dolerites (Olusegun et al. 1995; Folami 1992, Rahaman 1976).

The Ijebu-Jesa segment of the Ilesha schist belt falls into the migmatite-gneiss group with meta-sedimentary

Fig. 4 Schematic diagram of the ANN architecture used for the study

Overburden
Resistivity

OT

AQR

AQT

COA assemblages chiefly found as quartz schist. The quartz schist was mainly exposed by erosion within the study area (Fig. 2).

\section{Methodologies}

The study was executed in three phases which were groundwater level measurements, geophysical survey and prediction of groundwater level using ANN. The detail descriptions of methodology used in each of the phases are presented in "Groundwater level measurements"-"Prediction using artificial neural network (ANN)" sections below.

\section{Groundwater level measurements}

A total number of fifty-one (51) wells were accessible in the study area. The well location is shown in Fig. 3. The static water level and depth to the bottom of each well were determined at the peaks of dry and raining seasons and mean values obtained from the values obtained from the two seasons. In order to justify the use of the mean value used for the data obtained for the two seasons, reliability of the mean was statistically examined by carrying out some measures of dispersion which include the range and mean deviation. The coefficient of variation $(\mathrm{CV})$, (the ratio of the standard deviation to the mean), was also determined to further ascertain the level of dispersion, occasioned by seasonal variation, on the values obtained in the two periods. The ground water level (GWL) was thereafter obtained from the two measured values.

\section{Geophysical survey}

The vertical electrical resistivity (VES) data were acquired using the Ohmega Terrameter and its accessories. A total of fifty-one (51) VES stations were occupied at each of the 
well location as shown in Fig. 3 (i.e., parametric VES). The Schlumberger array was adopted with electrode spacing $(\mathrm{AB} / 2)$ ranging from 1 to $100 \mathrm{~m}$. The coordinates of measurement station were taken using Garmin GPS 7.0. The VES data acquired were processed qualitatively and quantitatively. The qualitative analysis involved mere inspection of the curve for its type; the quantitative analysis on the other hand involved partial curve matching to generate geoelectric parameters that served as initial model parameters for subsequent computer iteration.

The information obtained from the results of the interpretation of the VES data was utilized to estimate the geoelectric parameters [aquifer resistivity (AQR), aquifer thickness (AQT), overburden resistivity (OR), overburden thickness and (OT) and coefficient of anisotropy (COA)] that were used as input parameters to develop the artificial neural network (ANN) model.

\section{Prediction using artificial neural network (ANN)}

Steps of the artificial neural network (ANN) as adopted in the study:

The final stage of the methodology was the implementation of the artificial neural network. Neural Network Toolbox in MATLAB Version (8.3) 2015 was used. A back projection based feed forward neural network was used to model the input and output parameters using MATLAB neural network toolbox. The procedural steps involved the following: parameters/variables selection, ANN architecture development, data processing and the model performance evaluation.

\section{Parameters/variables selection}

Five parameters [i.e., overburden resistivity (OR); aquifer resistivity (AQR); overburden thickness (OT), aquifer thickness (AQT)] and coefficient of anisotropy (COA) were used as the input parameters while the measured groundwater level (GWL) was the model output.

\section{Data processing}

Data preprocessing involves partitioning of the data into three sets which were the training, validation and testing sets in the ratio: 70:15:15, respectively. The training set was the largest set used by neural network to learn patterns present in the data. The $70 \%$ training set was selected randomly across the range of the whole data so as to ensure that the data contain sufficient representation of the patterns. This will enable the network to mimic the underlying relationship between input and output variables adequately. In order to shuffle the data, the training data were presented to the network in random order so as to ensure that the response of the training network will not vary with the order of pattern presentation (Manisha et al. 2008). Training was controlled by some conditions such as: the maximum number of iterations, target performance which specifies the tolerance between the neural network prediction and actual outputs, the maximum run time and the minimum allowed gradient. The desired results were generated in the output layer. The network achieves the desired learning by adjusting its interconnected weights continuously until there was a close match between the output from the neurons and the output from the training data. The difference between the predicted outputs and the original outputs is referred to as error. At the end of the training phase, the neural network correctly reproduced the target output values for the training data provided with minimal error. $15 \%$ of the data was used for testing, whereas the remaining $15 \%$ was allocated for model validation. The validation set was used to make a final check on the performance of the trained network after the completion of the training/testing processes. Validation set is an independent data set which was not used during training process. Performance criteria adopted in this study were mean square error (MSE) and regression coefficient $(R)$.

\section{ANN architecture development}

The architecture of neural network defines its structure. It is the most important part of ANN development. Different neural network architectures were developed in order to establish a relationship between the input and output. All the networks were of the feed forward type. An ANN consists of input, hidden and output layers as shown in Fig. 4. The network architectures were trained by varying the number of hidden layer and then by varying number of neurons in each hidden layer.

The process involves determining the number of input neurons, the number of output neurons, the number of hidden layers and number of neurons in the hidden layers. Since the numbers of input and output neurons are decided by the nature of the problem, the number of hidden layer and associated hidden neurons represent the major decision to be made in overall architecture design.

In order to simplify the network architecture and thus reduce computational effort, a single layer network was adopted. In addition to this, it has been established that a single layer feed forward network with sufficient neurons can adequately approximate any nonlinear function (Haykin 1999; Hornik 1991). Starting with two neurons and then increasing the number while monitoring the performance criteria for each resulting architecture each time, the training was carried out until there was no significant 
Table 1 Results of the groundwater level measurement

\begin{tabular}{lllll}
\hline Well no. & $\begin{array}{l}\text { Peak dry season } \\
\text { SWL }(\mathrm{m})\end{array}$ & $\begin{array}{l}\text { Peak raining sea- } \\
\text { son SWL (m) }\end{array}$ & $\begin{array}{l}\text { Average } \\
\text { SWL (m) }\end{array}$ & Well depth (m) \\
& & &
\end{tabular}

Groundwater level (GWL)

(m)

\begin{tabular}{|c|c|c|c|c|c|}
\hline 1 & 10 & 10.8 & 10.4 & 11.3 & 0.9 \\
\hline 2 & 5.3 & 5.9 & 5.6 & 7.4 & 1.8 \\
\hline 3 & 8.8 & 9.5 & 9.15 & 10.2 & 1.05 \\
\hline 4 & 9.5 & 10.6 & 10.05 & 11.3 & 1.25 \\
\hline 5 & 9.6 & 10.6 & 10.1 & 11.8 & 1.7 \\
\hline 6 & 11.1 & 11.9 & 11.5 & 13.2 & 1.7 \\
\hline 7 & 10.2 & 10.7 & 10.45 & 11.9 & 1.45 \\
\hline 8 & 10.3 & 10.9 & 10.6 & 12.8 & 2.2 \\
\hline 9 & 9.2 & 9.9 & 9.55 & 11.4 & 1.85 \\
\hline 10 & 12 & 13.1 & 12.55 & 14.3 & 1.75 \\
\hline 11 & 9.8 & 9 & 9.4 & 11.2 & 1.8 \\
\hline 12 & 7.5 & 8.4 & 7.95 & 9.9 & 1.95 \\
\hline 13 & 9.4 & 9.7 & 9.55 & 10.2 & 0.65 \\
\hline 14 & 8.3 & 8.4 & 8.35 & 10.6 & 2.25 \\
\hline 15 & 3.6 & 3.7 & 3.65 & 8.3 & 4.65 \\
\hline 16 & 7.2 & 9 & 8.1 & 10.7 & 2.6 \\
\hline 17 & 8.2 & 9.1 & 8.65 & 11.9 & 3.25 \\
\hline 18 & 11 & 11.6 & 11.3 & 13.9 & 2.6 \\
\hline 19 & 10.2 & 10.8 & 10.5 & 12.6 & 2.1 \\
\hline 20 & 8.1 & 8.8 & 8.45 & 10.3 & 1.85 \\
\hline 21 & 4.5 & 5.1 & 4.8 & 6.2 & 1.4 \\
\hline 22 & 5.1 & 5.5 & 5.3 & 6.8 & 1.5 \\
\hline 23 & 5.1 & 5 & 5.05 & 6.5 & 1.45 \\
\hline 24 & 6 & 6.7 & 6.35 & 7.5 & 1.15 \\
\hline 25 & 6.5 & 6.7 & 6.6 & 8 & 1.4 \\
\hline 26 & 5.3 & 5.4 & 5.35 & 7 & 1.65 \\
\hline 27 & 9.1 & 9.7 & 9.4 & 10.9 & 1.5 \\
\hline 28 & 9.7 & 10.5 & 10.1 & 11.6 & 1.5 \\
\hline 29 & 10.6 & 11.5 & 11.05 & 12.5 & 1.45 \\
\hline 30 & 10.8 & 11.9 & 11.35 & 12.9 & 1.55 \\
\hline 31 & 8.9 & 9.6 & 9.25 & 14.1 & 4.85 \\
\hline 32 & 8.9 & 9.4 & 9.15 & 13.7 & 4.55 \\
\hline 33 & 10.9 & 11.1 & 11 & 12.6 & 1.6 \\
\hline 34 & 11.6 & 12.4 & 12 & 13.1 & 1.1 \\
\hline 35 & 10.5 & 10.9 & 10.7 & 12.8 & 2.1 \\
\hline 36 & 10.6 & 10.8 & 10.7 & 12.5 & 1.8 \\
\hline 37 & 11.7 & 11.9 & 11.8 & 13.6 & 1.8 \\
\hline 38 & 10.9 & 11.6 & 11.25 & 12 & 0.75 \\
\hline 39 & 9.6 & 10.7 & 10.15 & 13.4 & 3.25 \\
\hline 40 & 9.8 & 10.1 & 9.95 & 13.6 & 3.65 \\
\hline 41 & 8.2 & 8.4 & 8.3 & 10.9 & 2.6 \\
\hline 42 & 8.9 & 10.3 & 9.6 & 12.7 & 3.1 \\
\hline 43 & 6.5 & 6.8 & 6.65 & 9.8 & 3.15 \\
\hline 44 & 7.5 & 8.1 & 7.8 & 10.6 & 2.8 \\
\hline 45 & 6.9 & 7.6 & 7.25 & 10.5 & 3.25 \\
\hline 46 & 8.7 & 9.4 & 9.05 & 11.8 & 2.75 \\
\hline 47 & 10.5 & 10.9 & 10.7 & 12.6 & 1.9 \\
\hline 48 & 10.2 & 10.6 & 10.4 & 13.5 & 3.1 \\
\hline 49 & 7.5 & 7.7 & 7.6 & 10.7 & 3.1 \\
\hline
\end{tabular}


Table 1 (continued)

\begin{tabular}{llllll}
\hline Well no. & $\begin{array}{l}\text { Peak dry season } \\
\text { SWL }(\mathrm{m})\end{array}$ & $\begin{array}{l}\text { Peak raining sea- } \\
\text { son SWL }(\mathrm{m})\end{array}$ & $\begin{array}{l}\text { Average } \\
\text { SWL }(\mathrm{m})\end{array}$ & Well depth $(\mathrm{m})$ & $\begin{array}{l}\text { Groundwater } \\
\text { level (GWL) } \\
(\mathrm{m})\end{array}$ \\
\hline 50 & 7.9 & 9 & 8.45 & 11.2 & 2.75 \\
51 & 7.6 & 9.1 & 8.35 & 11.5 & 3.15 \\
\hline
\end{tabular}

improvement in the error. In order to objectively evaluate the model performance, the mean square error (MSE) and regression coefficient $(R)$ were computed and are summarized.

\section{Model performance evaluation}

In order to assess the efficiency of the artificial neural network model, it was validated with $15 \%$ of the field data. The five parameters (i.e., OR, AQR, OT, AQT and COA) for all the validation data set represent the input parameters. These input parameters were put into the ANN model. The model separately simulated the input data to produce the output groundwater level (GWL). The model outputs $\left(P_{j}\right)$ were compared with the expected outputs $\left(T_{j}\right)$ (i.e., output from the field data measured). The efficiency of the model was determined by estimating the mean square error (MSE) and the regression coefficient $(R)$ for the model.

\section{Results and discussions}

\section{Results of the groundwater level measurements}

The results of the measurements obtained from the wells/ boreholes are presented in Table 1 . The value of the coefficient of variation (CV) as determined from the results shown on Table 1 is $0.2 \%$ while the range varies from -0.8 to 1.5 . The small values obtained for both the CV and the range are an indication that the dispersion is small suggesting that seasonal variation has little effect on the water fluctuation in the wells and this further justifies the use of average of the two values. The groundwater level (GWL) shown in the last column of Table 1 was used as the output parameter for the ANN model.

\section{Results of the geophysical survey}

The geoelectric parameters obtained from the results of the interpretation of the VES are presented in Table 2. The geoelectric sections developed from results of the interpretation of the VES revealed that the subsurface is largely characterized by a maximum of between three and four layers. These layers are the top soil, the weathered basement, the fractured basement layer and the fresh basement. The weathered and or the fractured basement constitute the aquifer in the area. In other words, weathered basement aquifer and fractured basement aquifer are the aquifer types obtainable in the area. It is also observed that all the wells/boreholes in the area tap water from the delineated aquifer, this thus suggests that there is justification for predicting groundwater level from the geoelectric parameters obtained from the results of parametric soundings carried in the study area. The parameters shown in Table 2 were used as the input parameters for the ANN model.

\section{Results of the ANN parameters selection}

Five parameters, OR, AQR, OT, AQT and COA, shown in Table 2 were selected and used as the input parameters for the ANN model. These five parameters had been established to be significantly controlling the flow and accumulation of groundwater in the basement complex terrain and particularly in the study area (Adiat et al. 2018).

\section{Results of the ANN data processing/ANN architecture development}

The parameters shown in Table 2 are randomly partitioned into three in the ratio 70:15:15 to represent training, testing and validation data, respectively.

The results of performance evaluation of several networks trained were compared. It was observed that the number of iterations required by each network architecture differs. This implies that the number of iterations required by each network architecture to converge is not constant and this accounts for different iteration numbers recorded for different architecture (Table 3).

The effect of network architecture on its performance is displayed in the table. No appreciable improvement was accomplished by the addition of extra neuron into the network before or after 22 hidden neurons.

Network with 22 hidden neurons gave the best validation performance values of $0.24903,0.99998,0.95223$ and 0.98731 for regression coefficient $(R)$, training, testing and validation, respectively. The closeness of the $R$ value to 1 is an indication that both the predicted output (i.e., model output) and the expected output (i.e., the output used for the simulation) are well fitted. 
Table 2 Geoelectric parameter for ANN input and output

\begin{tabular}{|c|c|c|c|c|c|c|}
\hline \multirow[t]{2}{*}{ Well no. } & \multicolumn{5}{|c|}{ ANN input } & \multirow{2}{*}{$\begin{array}{l}\text { ANN output } \\
\text { GWL }\end{array}$} \\
\hline & OR & OT & $\mathrm{AQR}$ & AQT & $\mathrm{COA}$ & \\
\hline 1 & 49 & 3 & 150 & 12.2 & 1.09 & 0.9 \\
\hline 2 & 73 & 0.5 & 43 & 10.2 & 1.01 & 1.8 \\
\hline 3 & 38 & 1.7 & 132 & 18.1 & 1.06 & 1 \\
\hline 4 & 677 & 3.5 & 191 & 9.4 & 1.17 & 1.2 \\
\hline 5 & 93 & 2.5 & 311 & 22 & 1.23 & 1.7 \\
\hline 6 & 425 & 0.5 & 215 & 15.1 & 1.01 & 1.7 \\
\hline 7 & 303 & 1.7 & 79 & 33.3 & 1.08 & 1.4 \\
\hline 8 & 32 & 0.4 & 52 & 10.6 & 1 & 2.2 \\
\hline 9 & 55 & 2.4 & 75 & 20.5 & 1.05 & 1.8 \\
\hline 10 & 115 & 12.6 & 50 & 7.4 & 1.13 & 1.7 \\
\hline 11 & 99 & 11.4 & 117 & 10.6 & 1.04 & 1.8 \\
\hline 12 & 63 & 0.6 & 56 & 16.7 & 1 & 1.9 \\
\hline 13 & 98 & 3.4 & 103 & 20.1 & 1.03 & 0.6 \\
\hline 14 & 73 & 4 & 82 & 26.1 & 1.01 & 2.2 \\
\hline 15 & 54 & 3.1 & 138 & 15 & 1.24 & 4.6 \\
\hline 16 & 275 & 4.9 & 115 & 16.5 & 1.2 & 2.6 \\
\hline 17 & 169 & 5.3 & 92 & 14.3 & 1.11 & 2.2 \\
\hline 18 & 102 & 11.2 & 85 & 36.2 & 1.06 & 2.6 \\
\hline 19 & 213 & 15.2 & 47 & 19.1 & 1.33 & 2.1 \\
\hline 20 & 215 & 5.4 & 34 & 18.8 & 1.92 & 1.8 \\
\hline 21 & 99 & 2.1 & 95 & 18 & 1 & 1.4 \\
\hline 22 & 71 & 0.8 & 144 & 3.4 & 1.03 & 1.5 \\
\hline 23 & 567 & 0.7 & 265 & 35.9 & 1.01 & 1.4 \\
\hline 24 & 474 & 6 & 129 & 20.2 & 1.27 & 2.1 \\
\hline 25 & 121 & 0.5 & 254 & 17.2 & 1.01 & 1.4 \\
\hline 26 & 358 & 20.9 & 61 & 18.1 & 1.02 & 1.6 \\
\hline 27 & 90 & 3.1 & 23 & 3.9 & 1.24 & 1.5 \\
\hline 28 & 51 & 10.3 & 145 & 11.9 & 1.26 & 1.5 \\
\hline 29 & 404 & 8.9 & 167 & 12.6 & 1.28 & 1.4 \\
\hline 30 & 349 & 3.5 & 260 & 22.7 & 1.03 & 1.5 \\
\hline 31 & 100 & 0.4 & 294 & 1.7 & 1.09 & 4.8 \\
\hline 32 & 710 & 6 & 649 & 2.4 & 2.64 & 4.5 \\
\hline 33 & 76 & 0.5 & 82 & 1.7 & 1 & 1.6 \\
\hline 34 & 135 & 17.1 & 143 & 18.8 & 1.04 & 1.1 \\
\hline 35 & 734 & 11.6 & 347 & 50.9 & 1.19 & 2.1 \\
\hline 36 & 946 & 30.3 & 312 & 48.2 & 1.37 & 1.7 \\
\hline 37 & 157 & 2.4 & 49 & 49.1 & 1.06 & 1.8 \\
\hline 38 & 262 & 4 & 102 & 15.1 & 1.18 & 0.7 \\
\hline 39 & 821 & 13.4 & 229 & 40.2 & 1.61 & 3.2 \\
\hline 40 & 1426 & 31.4 & 387 & 43.5 & 1.13 & 3.6 \\
\hline 41 & 608 & 15 & 382 & 41.6 & 1.11 & 2.6 \\
\hline 42 & 467 & 5 & 123 & 23.7 & 1.29 & 3.1 \\
\hline 43 & 598 & 15.5 & 510 & 28.1 & 1.1 & 2.1 \\
\hline 44 & 81 & 0.4 & 83 & 1.6 & 1 & 2.8 \\
\hline 45 & 112 & 0.4 & 204 & 1.8 & 1.03 & 3.2 \\
\hline 46 & 187 & 0.4 & 161 & 5.9 & 1 & 2.7 \\
\hline 47 & 1083 & 12.9 & 289 & 38 & 1.32 & 1.9 \\
\hline 48 & 131 & 2.6 & 13 & 14.9 & 1.43 & 3.1 \\
\hline 49 & 207 & 0.7 & 137 & 3.8 & 1.62 & 3.1 \\
\hline
\end{tabular}


Table 2 (continued)

\begin{tabular}{lllllll}
\hline Well no. & \multicolumn{1}{l}{ ANN input } & & & & \multicolumn{2}{c}{$\begin{array}{l}\text { ANN output } \\
\end{array}$} \\
\cline { 2 - 6 } & OR & OT & AQR & AQT & COA & GWL \\
\hline 50 & 1528 & 7.9 & 228 & 12.1 & 1.78 & 2.7 \\
51 & 138 & 2.6 & 570 & 19.1 & 1.11 & 3.1 \\
\hline
\end{tabular}

Table 3 Summary of performance evaluations of ANN architectures

\begin{tabular}{lllllllc}
\hline Network architecture & $\begin{array}{l}\text { Best valida- } \\
\text { tion perfor- } \\
\text { mance }\end{array}$ & $\begin{array}{l}\text { Regression }(R) \\
\text { for training set }\end{array}$ & $\begin{array}{l}\text { Regression } \\
(R) \text { for test- } \\
\text { ing }\end{array}$ & $\begin{array}{l}\text { Regression }(R) \\
\text { for validation } \\
\text { set }\end{array}$ & Regression for all & $\begin{array}{l}\text { No. of } \\
\text { itera- } \\
\text { tion }\end{array}$ & $\begin{array}{l}\text { No. of iteration at best } \\
\text { validation performance }\end{array}$ \\
\hline Net 1 [2] & 2.2722 & 0.99988 & 0.88445 & 0.76175 & 0.95592 & 10 & 4 \\
Net 1 [4] & 2.7091 & 0.99998 & 0.9654 & 0.86818 & 0.97183 & 12 & 6 \\
Net 1 [6] & 4.1692 & 0.99999 & 0.80165 & 0.8659 & 0.94508 & 17 & 11 \\
Net 1 [8] & 1.2842 & 0.99999 & 0.89737 & 0.94787 & 0.96579 & 19 & 13 \\
Net 1 [10] & 6.1707 & 0.99999 & 0.0912 & 0.86232 & 0.94561 & 9 & 3 \\
Net 1 [12] & 0.4430 & 1 & 0.87559 & 0.97646 & 0.97688 & 23 & 17 \\
Net 1 [14] & 0.47164 & 1 & 0.7688 & 0.97842 & 0.96154 & 72 & 69 \\
Net 1 [16] & 8.8022 & 0.99999 & 0.72823 & 0.51562 & 0.87995 & 9 & 3 \\
Net 1 [18] & 0.46045 & 0.99774 & 0.83706 & 0.97405 & 0.9527 & 7 & 1 \\
Net 1 [20] & 1.1959 & 0.99999 & 0.95982 & 0.92252 & 0.9773 & 22 & 16 \\
Net 1 [22] & 0.24903 & 0.99998 & 0.95223 & 0.98534 & 0.98731 & 11 & 5 \\
Net 1 [28] & 4.8064 & 0.99792 & 0.91356 & 0.66195 & 0.93569 & 7 & 1 \\
Net 1 [30] & 1.9216 & 0.99999 & 0.79642 & 0.95931 & 0.95639 & 34 & 28
\end{tabular}

Apart from the best performance in terms of MSE and $R$, network with 22 neurons provides simpler architecture needed for better computational efficiency when compared to others. Consequently, the network with 5 inputs, 22 hidden neurons and 1 output neuron was selected.

\section{Results of the ANN model performance evaluation}

Figure 5 is the regression coefficient $(R)$ plot for the best architecture of 22 hidden layers. For training, neural network fits data along the blue line, the actual network outputs plotted in terms of the associated target values and $R$ for training is $\mathbf{0 . 9 9 9 9 8}$ which is high and close to 1 . The closeness of the $R$ value to 1 is an indication that both the predicted output and the expected output are well fitted. For testing, neural network fits data along the red line, the actual network outputs plotted in terms of the associated target values and $R$ for testing is $\mathbf{0 . 9 5 2 2 3}$. Validation data fit on the green light with $R$ value of $\mathbf{0 . 9 8 5 3 4}$. The value of $R$ for all training, testing and validation simulated together is $\mathbf{0 . 9 8 7 3 1}$. The closeness of the $R$ value to 1 is an indication that the model fits the data well with accurate prediction of the groundwater level.

The results obtained from training of the data are presented in Table 4. The outputs generated by the ANN model [i.e., the predicted output $\left.\left(P_{j}\right)\right]$ as compared with the output used for the model training [i.e., the expected output $\left(T_{j}\right)$ ] are shown in the table. The mean square error (MSE) (one of the criteria used to evaluate the effectiveness of the performance of the model is shown in the table while the regression coefficient $(R)$ had earlier been presented in Fig. 5).

The validation results for the ANN models are presented in Table 5. The mean square prediction error as shown in the table is 0.0014286 suggesting that the error limit of the prediction accuracy of the ANN model is $\mathbf{0 . 0 0 1 4 2 8 6}$. The regression value of 0.98534 was obtained for the ANN model (Fig. 6). The regression coefficient values of $\mathbf{0 . 9 8 5 3 4}$ obtained for the $A N N$ model indicate that the output values of the validation data and the expected output are well fitted in the model. Furthermore, the closeness of the regression value to 1 in the ANN model is an indication that the model is efficient in terms of groundwater level prediction.

High $R$ value and small MSE value obtained ANN show that the model fits the data well. The results obtained from analysis of the data clearly showed that ANN model is best fit for predicting the groundwater level. This suggests that model can be applied in other areas of similar geology. 
Fig. 5 Regression plot for neural network with 22 neurons (hidden layers)
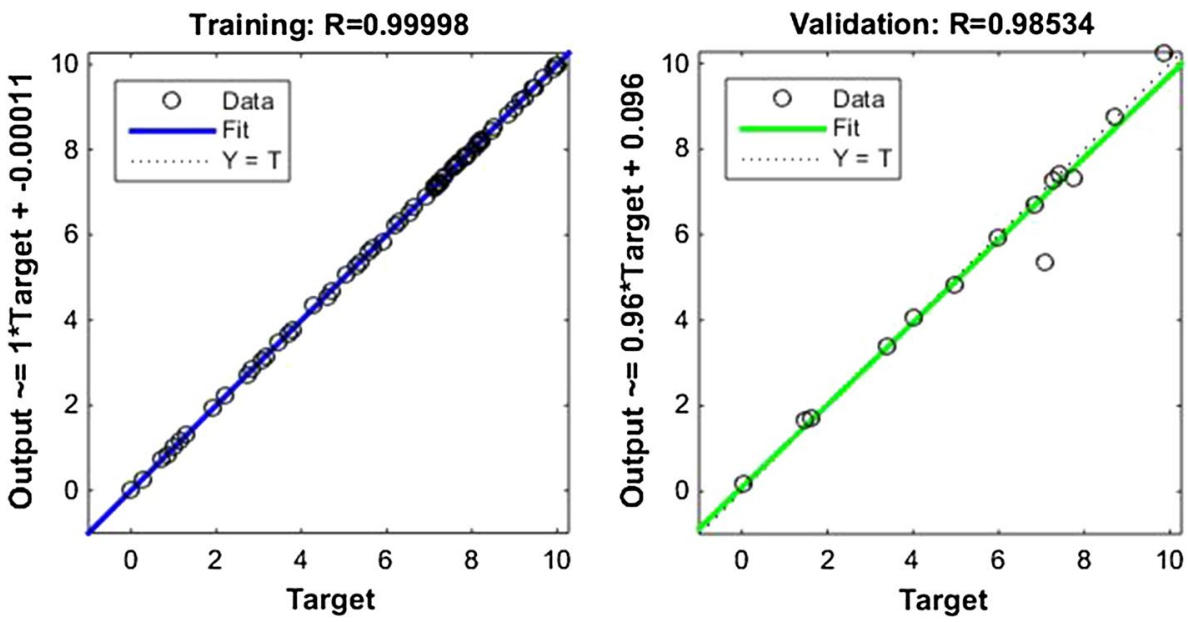

Test: $\mathbf{R}=0.95223$
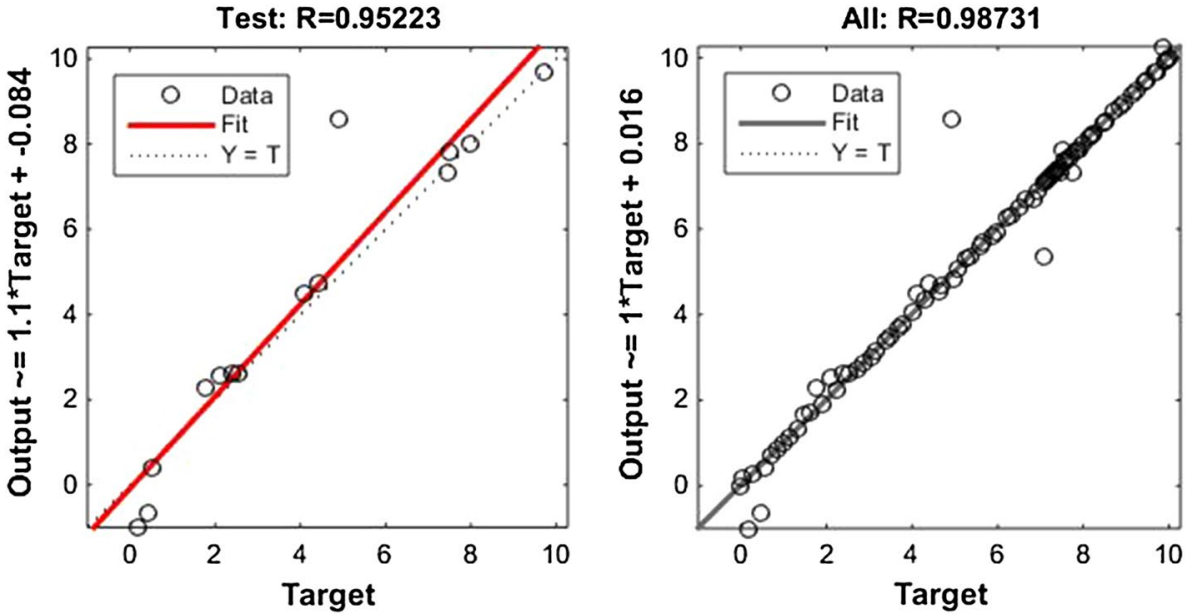

\section{Conclusion}

Prediction of groundwater level (GWL) from geoelectric parameters is still a challenge in groundwater studies. This is partly because the empirical relationship between groundwater level and geoelectric parameters has hitherto not been established. An attempt was made in this study to overcome these challenges by exploring the capability of artificial neural network (ANN) to model nonlinear system.

In order to achieve the objectives of the study, the piezometric head parameters of fifty-one (51) accessible wells in the study area were measured at the peaks of dry and raining seasons. These were used to obtain the GWL in these wells having established that a seasonal variation does not have significant effect on the groundwater fluctuation in the area. The GWL so obtained was used as the output parameter for the ANN model.

A total of fifty-one (51) parametric vertical electrical soundings (VES) stations were occupied at each of the well location by adopting Schlumberger array configuration with electrode spacing $(\mathrm{AB} / 2)$ ranging from 1 to $100 \mathrm{~m}$. The results obtained from the quantitative interpretation of the VES data were used to generate geoelectric parameters which include aquifer resistivity (AQR), aquifer thickness (AQT), overburden resistivity (OR), overburden thickness and (OT) and coefficient of anisotropy (COA). These parameters had been established to be controlling the groundwater flow and storage in the basement complex terrain and particularly the study area. These geoelectric parameters served as the input parameters for ANN model.

The capability of ANN as a nonlinear modeling system was thereafter applied to produce a model that can predict the GWL from the input parameters. The efficiency of the model was evaluated by estimating the mean square error (MSE) and the regression coefficient $(R)$ for the model.

The results established that seasonal variation has little effect on the water fluctuation in the wells. The geoelectric sections developed from results of the interpretation of the VES revealed that the subsurface is largely characterized by a maximum of between three and four layers which are the top soil, the weathered basement, the fractured basement layer and the fresh basement. Two aquifer types (weathered basement aquifer and fractured basement aquifer) are obtainable in the area. It was also established that all the wells/

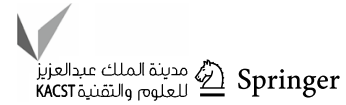


Table 4 ANN summary table for training data set

\begin{tabular}{|c|c|c|c|c|c|c|c|c|}
\hline \multicolumn{5}{|c|}{ Input parameters } & \multirow{2}{*}{$\begin{array}{l}\text { Measured GWL } \\
\text { output }\left(T_{j}\right)\end{array}$} & \multirow{2}{*}{$\begin{array}{l}\text { ANN model predicted } \\
\text { GWL output }\left(P_{j}\right)\end{array}$} & \multirow{2}{*}{$\begin{array}{l}\text { Prediction error } \\
\left(T_{j}-P_{j}\right)\end{array}$} & \multirow{2}{*}{$\begin{array}{l}\text { Square of } \\
\text { prediction } \\
\text { error } \\
\left(T_{j}-P_{j}\right)^{2}\end{array}$} \\
\hline $\mathrm{OR}(\Omega \mathrm{m})$ & OT (m) & $\mathrm{AQR}(\Omega \mathrm{m})$ & AQT (m) & $\mathrm{COA}$ & & & & \\
\hline 49 & 3 & 150 & 12.2 & 1.09 & 0.9 & 0.9 & 0 & 0 \\
\hline 73 & 0.5 & 43 & 10.2 & 1.01 & 1.8 & 1.2 & 0.6 & 0.36 \\
\hline 677 & 3.5 & 191 & 9.4 & 1.17 & 1.2 & 1.2 & 0 & 0 \\
\hline 93 & 2.5 & 311 & 22 & 1.23 & 1.7 & 1.7 & 0 & 0 \\
\hline 425 & 0.5 & 215 & 15.1 & 1.01 & 1.7 & 1.7 & 0 & 0 \\
\hline 303 & 1.7 & 79 & 33.3 & 1.08 & 1.4 & 1.4 & 0 & 0 \\
\hline 32 & 0.4 & 52 & 10.6 & 1 & 2.2 & 2.2 & 0 & 0 \\
\hline 55 & 2.4 & 75 & 20.5 & 1.05 & 1.8 & 1.8 & 0 & 0 \\
\hline 115 & 12.6 & 50 & 7.4 & 1.13 & 1.7 & 1.7 & 0 & 0 \\
\hline 63 & 0.6 & 56 & 16.7 & 1 & 1.9 & 1.9 & 0 & 0 \\
\hline 98 & 3.4 & 103 & 20.1 & 1.03 & 0.6 & 0.6 & 0 & 0 \\
\hline 73 & 4 & 82 & 26.1 & 1.01 & 2.2 & 2.2 & 0 & 0 \\
\hline 54 & 3.1 & 138 & 15 & 1.24 & 4.6 & 4.6 & 0 & 0 \\
\hline 275 & 4.9 & 115 & 16.5 & 1.2 & 2.6 & 2.6 & 0 & 0 \\
\hline 102 & 11.2 & 85 & 36.2 & 1.06 & 2.6 & 2.6 & 0 & 0 \\
\hline 213 & 15.2 & 47 & 19.1 & 1.33 & 2.1 & 2.1 & 0 & 0 \\
\hline 99 & 2.1 & 95 & 18 & 1 & 1.4 & 1.4 & 0 & 0 \\
\hline 71 & 0.8 & 144 & 3.4 & 1.03 & 1.5 & 1.5 & 0 & 0 \\
\hline 567 & 0.7 & 265 & 35.9 & 1.01 & 1.4 & 1.4 & 0 & 0 \\
\hline 474 & 6 & 129 & 20.2 & 1.27 & 2.1 & 2.1 & 0 & 0 \\
\hline 51 & 10.3 & 145 & 11.9 & 1.26 & 1.5 & 1.5 & 0 & 0 \\
\hline 404 & 8.9 & 167 & 12.6 & 1.28 & 1.4 & 1.4 & 0 & 0 \\
\hline 349 & 3.5 & 260 & 22.7 & 1.03 & 1.5 & 1.5 & 0 & 0 \\
\hline 76 & 0.5 & 82 & 1.7 & 1 & 1.6 & 1.6 & 0 & 0 \\
\hline 135 & 17.1 & 143 & 18.8 & 1.04 & 1.1 & 1.1 & 0 & 0 \\
\hline 734 & 11.6 & 347 & 50.9 & 1.19 & 2.1 & 2.1 & 0 & 0 \\
\hline 946 & 30.3 & 312 & 48.2 & 1.37 & 1.7 & 1.7 & 0 & 0 \\
\hline 157 & 2.4 & 49 & 49.1 & 1.06 & 1.8 & 1.8 & 0 & 0 \\
\hline 262 & 4 & 102 & 15.1 & 1.18 & 0.7 & 0.7 & 0 & 0 \\
\hline 821 & 13.4 & 229 & 40.2 & 1.61 & 3.2 & 3.2 & 0 & 0 \\
\hline 1426 & 31.4 & 387 & 43.5 & 1.13 & 3.6 & 3.6 & 0 & 0 \\
\hline 467 & 5 & 123 & 23.7 & 1.29 & 3.1 & 3.1 & 0 & 0 \\
\hline 81 & 0.4 & 83 & 1.6 & 1 & 2.8 & 2.8 & 0 & 0 \\
\hline 131 & 2.6 & 13 & 14.9 & 1.43 & 3.1 & 3.1 & 0 & 0 \\
\hline 207 & 0.7 & 137 & 3.8 & 1.62 & 3.1 & 3.1 & 0 & 0 \\
\hline 1528 & 7.9 & 228 & 12.1 & 1.78 & 2.7 & 2.7 & 0 & 0 \\
\hline 138 & 2.6 & 570 & 19.1 & 1.11 & 3.1 & 3.1 & 0 & 0 \\
\hline & & & & & & & $\begin{array}{l}\text { Mean square of pre- } \\
\text { diction error }=0.01\end{array}$ & \\
\hline
\end{tabular}

boreholes in the area tap water from the delineated aquifer, this thus suggests that there is justification for predicting groundwater level from the geoelectric parameters obtained from the results of parametric soundings carried in the study area.

The data set was partitioned into training, testing and validation in ratio the 70:15:15, respectively. Apart from the best performance in terms of MSE and $R$, network with 22 neurons provides simpler architecture needed for better computational efficiency when compared to others. Consequently, the network with 5 inputs, 22 hidden neurons and 1 output neuron was selected.

For training, neural network fits data and $R$ for training is $\mathbf{0 . 9 9 9 9 8}$ which is high and close to 1 . The closeness of the 
Table 5 Table for validation data set

\begin{tabular}{|c|c|c|c|c|c|c|c|c|}
\hline \multicolumn{5}{|c|}{ Input parameters } & \multirow{2}{*}{$\begin{array}{l}\text { Measured GWL } \\
\text { output }\left(T_{j}\right)\end{array}$} & \multirow{2}{*}{$\begin{array}{l}\text { ANN model predicted } \\
\text { GWL output }\left(P_{j}\right)\end{array}$} & \multirow{2}{*}{$\begin{array}{l}\text { Prediction } \\
\text { error }\left(T_{j}-P_{j}\right)\end{array}$} & \multirow{2}{*}{$\begin{array}{l}\text { Square of } \\
\text { prediction error } \\
\left(T_{j}-P_{j}\right)^{2}\end{array}$} \\
\hline $\mathrm{OR}(\Omega \mathrm{m})$ & OT (m) & $\mathrm{AQR}(\Omega \mathrm{m})$ & AQT (m) & $\mathrm{COA}$ & & & & \\
\hline 38 & 1.7 & 132 & 18.1 & 1.06 & 1 & 1.1 & -0.1 & 0.01 \\
\hline 169 & 5.3 & 92 & 14.3 & 1.11 & 2.2 & 2.2 & 0 & 0 \\
\hline 215 & 5.4 & 34 & 18.8 & 1.92 & 1.8 & 1.8 & 0 & 0 \\
\hline 90 & 3.1 & 23 & 3.9 & 1.24 & 1.5 & 1.5 & 0 & 0 \\
\hline 608 & 15 & 382 & 41.6 & 1.11 & 2.6 & 2.6 & 0 & 0 \\
\hline 598 & 15.5 & 510 & 28.1 & 1.1 & 2.1 & 2.1 & 0 & 0 \\
\hline 112 & 0.4 & 204 & 1.8 & 1.03 & 3.2 & 3.2 & 0 & $\begin{array}{l}0 \\
\mathrm{MSE}=0.0014286\end{array}$ \\
\hline
\end{tabular}

$R$ value to 1 is an indication that both the predicted output and the expected output are well fitted. For testing, neural network fits and $R$ for testing is $\mathbf{0 . 9 5 2 2 3}$. The model was validated using validation data set which is $15 \%$ of the data set and randomly selected. The results of the validation showed that the mean square error (MSE) and the regression coefficient $(R)$ for the ANN model were $\mathbf{0 . 0 0 1 4 2 8 6}$ and $\mathbf{0 . 9 8 7 3 1}$, respectively. The results obtained from the validation of the ANN techniques showed that the modeling technique has effectiveness in predicting the groundwater level. This shows that the model is capable of producing effective and reliable prediction results. The model can be applied in other areas of similar geology. Therefore, from the study, the results are satisfactory and demonstrate that neural networks can be a useful prediction tool and it can be concluded that ANN is an effective tool for predicting groundwater level for the

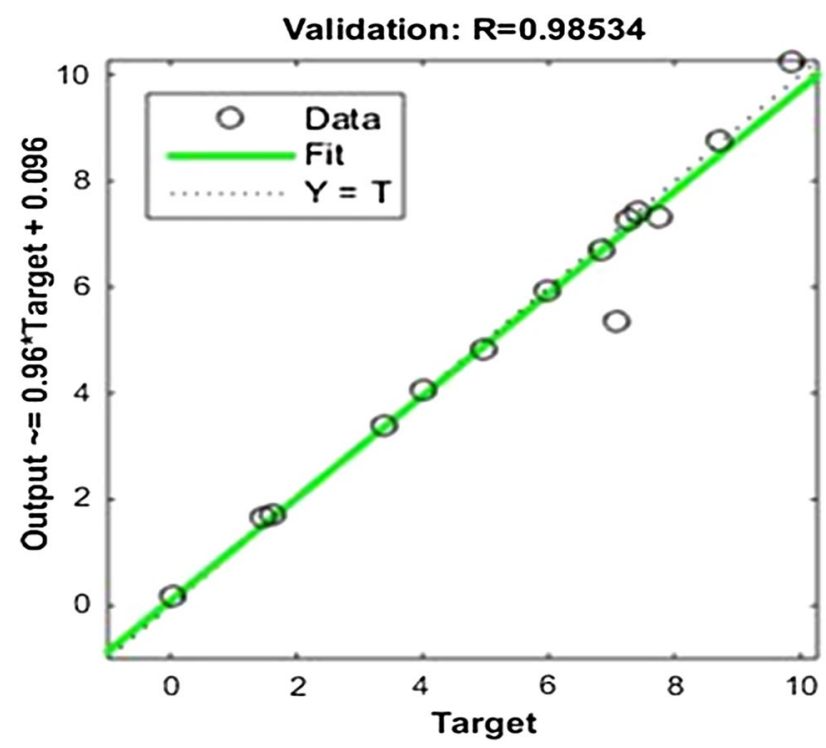

Fig. 6 Regression plot for the validation of the ANN model with 22 hidden layers purposes of effective planning and management of groundwater resources.

Open Access This article is distributed under the terms of the Creative Commons Attribution 4.0 International License (http://creativeco mmons.org/licenses/by/4.0/), which permits unrestricted use, distribution, and reproduction in any medium, provided you give appropriate credit to the original author(s) and the source, provide a link to the Creative Commons license, and indicate if changes were made.

\section{References}

Abdul RS, Umar H, Zuraidah R (2001) Geophysical investigation of the Olak Lempit Quaternary Basin, Selangor, Malaysia. In: Proceedings of 10th GEOSEA regional congress on geology, mineral and energy resources, Jogjakarta, Indonesia, pp 280-282

Adiat KAN, Nawawi MNM, Abdullah K (2012) Assessing the accuracy of GIS-based elementary multi criteria decision analysis as a spatial prediction tool-a case of predicting potential zones of sustainable groundwater resources. J Hydrol. https://doi. org/10.1016/j.jhydrol.2012.03.028

Adiat KAN, Nawawi MNM, Abdullah K (2013) Application of multicriteria decision analysis to geoelectric and geologic parameters for spatial prediction of groundwater resources potential and aquifer evaluation. Pure Appl Geophys 170:453-471. https://doi. org/10.1007/s00024-012-0501-9

Adiat KAN, Osifila AJ, Akinlalu AA, Alagbe OA (2018) Mining of geophysical data to predict groundwater prospect in a basement complex terrain of southwestern Nigeria. Int J Sci Technol Res 7(5). ISSN 2277-8616

Ajayi TR, Ogedengbe O (2003) Opportunity for the exploitation of precious and rare metals in Nigeria. In: Elueze AA (ed) Prospects for investment in mineral resources of southwestern Nigeria. Nigerian Mining and Geosciences Society (NMGS) Nigeria, pp 15-26

Ajmera TK, Rastogi AK (2008) Artificial neural network application on estimation of aquifer transmissivity. J Spat Hydrol 8(2):15-31

Aziz ARA, Wong KFV (1992) Neural network approach for the determination of aquifer parameters. Groundwater 30(2):164-166

Brion GM, Neelakantan TR, Lingireddy S (2002) A neuralnetworkbased classification scheme for sorting sources and ages of fecal contamination in water. Water Res 36:3765-3774

Coppola E, Szidarovszky F, Poulton M, Charles E (2003) Artificial neural network approach for predicting transient water levels in 
multilayered groundwater system under variable state, pumping and climatic conditions. J Hydrol Eng 8(6):348-380

Coppola EA Jr, Szidarovszky F, Davis D, Spayd S, Poulton MM, Roman E (2007) Multiobjective analysis of a public wellfield using artificial neural networks. Ground Water 45(1):53-61

Daliakopoulos IN, Coulibaly P, Tsanis IK (2005) Groundwater level forecasting using artificial neural networks. J Hydrol 309:229-240

Elueze A (1986) Geology of the Precambrian Nigeria, Nigeria. Geological Survey, pp 77-82

Esmaili VM (2003) Presenting an intelligent model for estimating the fluctuation of alluvial aquifer groundwater level by using artificial neural network. Paper presented at the first two yearly conference of managing resources of Iran

Folami L (1992) Interpretation of aero magnetic anomalies in Iwaraja area, Southwestern Nigeria. J Min Geol 28(2):391-396

French MN, Krajewski WF, Cuykendall RR (1992) Rainfall forecasting in space and time using a neural network. J Hydrol 137:1-31

Gemitzi A, Petalas C, Pisinaras V, Tsihrintzis VA (2009) Spatial prediction of nitrate pollution in groundwaters using neural networks and GIS: an application to South Rhodope aquifer (Thrace, Greece). Hydrol Process 23:372-383. https://doi.org/10.1002/ hyp. 7143

Gumrah F, Oz B, Guler B, Evin S (2000) The application of artificial neural networks for the prediction of water quality of polluted aquifer. J Water Air Soil Pollut 119:275-294

Haykin S (1999) Neural networks: a comprehensive foundation, 2nd edn. Prentice Hall, Englewood Cliffs

Hill T, O'Connor M, Remus W (1996) Neural network models for time series forecasts. Manag Sci 42:1082-1092

Hoque MA, Khan AA, Shamsudduha M, Hossain MS, Islam T, Chowdhury SH (2009) Near surface lithology and spatial variation of arsenic in the shallow groundwater: southeastern Bangladesh. Environ Geol 56:1687-1695. https://doi.org/10.1007/s0025 4-008-1267-3

Hornik K (1991) Approximation capabilities of multilayer feedforward networks. Neural Netw 4(2):251-257

Kayode JS (2006). Ground magnetic study of Jeda-Iloko area, Southwestern Nigeria and its geologic implications. Unpublished M. Tech. Thesis submitted to the Department of Applied Geophysics, Federal University of Technology, Akure, Nigeria

Lallahem S, Mania J, Hani A, Najjar Y (2005a) On the use of neural networks to evaluate groundwater levels in fractured media. $\mathrm{J}$ Hydrol 307:92-111

Lallahem S, Mania J, Hani A, Najjar Y (2005b) On the use of neural networks to evaluate groundwater levels in fractured porous media. J Math Comput Model 37:1047-1061

Li H, Lu Y, Zheng C, Yang M, Li S (2019) Groundwater level prediction for the arid oasis of Northwest China based on the artificial bee colony algorithm and a back-propagation neural network with double hidden layers. Water 11:860. https://doi.org/10.3390/ w11040860

Manisha PJ, Rastogi AK, Mohan BK (2008) Critical review of applications of artificial neural networks in groundwater hydrology. In: The 12th international conference of international association for computer methods and advances in geomechanics (IACMAG) 1-6 October, 2008 Goa, India

Mao X, Shang S, LIiu X (2002) Groundwater level predictions using artificial neural networks. Tsinghua Sci Technol 7(6):574-579, ISSN 1007-0214 04/20

Nair SS, Sindhu G (2016) Groundwater level forecasting using artificial neural network. Int J Sci Res Publ 6(1), ISSN 2250-3153

Odeyemi IB (1993) A comparative study of remote sensing images of the structure of okemesi fold belt, Nigeria. ITC J. 1, 77-83

Olusegun O, Kehinde P, Gerd F (1995) The mineralogy and geochemistry of the weathering profiles over amphibolite, anthophilite and talcshicsts in Ilesa Schist Belt, Southwestern Nigeria. J Min Geol 31(1):53-62

Parkin G, Birkinshaw SJ, Younger PL, Rao Z, Kirk S (2007) A numerical modelling and neural network approach to estimate the impact of groundwater abstractions on river fows. J Hydrol 339:15-28

Rahaman MA (1976) A review of the basement geology of southwestern Nigeria. In: Kogbe CA (ed) Geology of Nigeria. Elizabeth Publishing Co, UK, pp 41-58

Shaouuan F, Shaozhang K, Zailin H, Shaqiun C, Xiaomin M (2007) Neural networks to simulate regional groundwater levels affected by human activities. Groundwater 46(1):80-90

Sreekanth PD, Geethanjali N, Sreedevi PD, Shakeel A, Ravi Kumar N, Kamala J (2009) Forecasting groundwater level using artificial neural networks. Curr Sci 96:933-939

Tang Z, Fishwick PA (1993) Feedforward neural nets as models for time series forecasting. ORSA J Comput 5:374-385

Yan S, Minsker B (2006) Optimal groundwater remediation design using an adaptive neural network genetic algorithm. Water Res Res 42(5):42-46

Zakari A, Robert N, Philippe NN, Jamal A (2015) Aquifers productivity in the Pan-African context. J Earth Syst Sci 124(3):527-539

Zhang G (2003) Time series forecasting using a hybrid ARIMA and neural network model. Neurocomputing 50:159-175

Zhao Y, Nan J, Cui F, Guo L (2007) Water quality forecast through application of BP neural network at Yuqiao reservoir. J Zhejiang Univ Sci A 8:1482-1487

Publisher's Note Springer Nature remains neutral with regard to jurisdictional claims in published maps and institutional affiliations. 